\title{
RELATOS DE VIAGENS COMO OBJETOS DE REFLE- XÃO HISTORIOGRÁFICA E DA PRÁTICA TRADUTÓRIA
}

\author{
Luiz Barros Montez \\ Universidade Federal do Rio de Janeiro
}

\begin{abstract}
Resumo: Relatos de viagens formam um campo discursivo específico, que suscita reflexões sobre o fazer tradutório indissociáveis das reflexões sobre o fazer historiográfico enquanto prática discursiva. Isso evidencia a necessidade do exame desses relatos em termos não exclusivamente textuais. Segundo alguns novos paradigmas propostos pelo campo do que chamamos de Análise do Discurso Crítica, os relatos podem ser vistos como práticas simultaneamente de representação, de ação social e de constituição de identidades. Com base nessa constatação e em algumas de suas implicações, sugere-se que a atividade de tradução de relatos de viagens não seja realizada apenas com base em propósitos hermenêuticos 'presentistas', mas também atenta à interpretação do passado em termos historiográficos.
\end{abstract}

Palavras-chave: Relatos de viagens. Tradução. Historiografia. Análise do Discurso Crítica.

\footnotetext{
* Formação em Português Alemão, Universidade Federal do Rio de Janeiro. Atualização em Língua e Literatura Alemã, Universidade de Freiburg. Mestrado em Língua e Literatura Alemã, Universidade Federal do Rio de Janeiro. Doutorado em Letras (Língua e Literatura Alemã), Universidade de São Paulo. Pós-Doutorado em Linguística Aplicada, Universidade de Viena. Professor Associado da Faculdade de Letras da Universidade Federal do Rio de Janeiro. Rio de Janeiro, Rio de Janeiro, Brasil. E-mail: lmontez@letras.ufrj.br
} 


\title{
TRAVEL ACCOUNTS AS OBJECTS OF REFLECTION ON HISTORIOGRAPHY AND TRANSLATING PRACTICE
}

\begin{abstract}
Travel accounts make up a specific discursive field that requires reflections on the practice of translating which are indissolubly linked with reflections on historiography as a discursive practice. This fact points out the necessity of the examining of those accounts not exclusively as a text-limited issue. According to new paradigms brought up in the field of the so called Critical Discourse Analysis, the accounts could be regarded simultaneously as representational, actional and ideational (i.e. identity forming) practice. Based upon that and some of its consequences, the article suggests that translating travel accounts should not be carried out only for the purpose of hermeneutic 'immediacy', but also guided by the interpretation of the past in historiographical terms.

Keywords: Travel accounts. Translation. Historiography. Critical Discourse Analysis.
\end{abstract}

\section{O documento, sua natureza}

Um texto escrito no passado pode trazer mais ou menos informação historiográfica acerca da época de sua produção, dependendo não somente de sua natureza, mas também do modo como ele é investigado. Vale dizer, um único e mesmo texto pode mostrar-se opaco ou pouco informativo para um historiador, enquanto para outro se mostra elucidativo e rico em informações. Examinado do ponto de vista de suas razões semânticas mais profundas, ou seja, como um "enunciado" (cf. BAKHTIN, 2003), o objeto textual pode se apresentar como homogêneo e simples, para um investigador, ao mesmo tempo em que se apresenta atravessado por fraturas e como um objeto complexo para outro. Este último investigador, munido com um arsenal teórico que dê conta destas fraturas, certamente estará mais habilitado a extrair do texto um maior número de informações, e mais ricas, do que o primeiro.

Um historiador pode e deve ter consciência de que por trás da superfície aparentemente "lisa" de um documento textual podem 
ocultar-se em maior ou menor medida rupturas, contradições, descontinuidades, silêncios. Estas "asperezas”, expressas na própria substância (ou na ausência) dos signos verbais (morfológicos, sintáticos, paragrafais, nominais, verbais, modalizantes, coesionadores ou [des] estruturadores, com extensões de um simples morfema até as bem mais dilatadas), problematizam, no plano intratextual, a definição dos objetos, dos modos, das modalidades enunciativas, dos conceitos e das estratégias discursivas, conforme nos sugere Foucault em sua Arqueologia (2008). Embora nesta obra mesma o autor não se proponha a isso, ao reconhecer "no próprio tecido documental, as unidades, conjuntos, séries, relações”, Foucault sugere caminhos ainda inexplorados através dos quais a análise do discurso poderá vir a se constituir numa alavanca indispensável para o exame historiográfico acurado de determinados corpora textuais (FOUCAULT, 2008, p. 7) ${ }^{1}$.

Parece bastante claro que, para que isso possa ser realizado, é fundamental reconhecer o documento textual como prática social concreta em meio aos conflitos e interesses econômicos, políticos e ideológicos da época em que foi produzido. Contudo, o que não é tão claro é que, para se levar a cabo esse reconhecimento, não basta o levantamento das condições históricas em que o texto em questão foi escrito - aí incluída a biografia do autor, ou mesmo a investigação de suas motivações psicológicas - desvinculado dos seus aspectos linguísticos constitutivos particulares. É imprescindível o reconhecimento prévio do texto como prática discursiva específica, isto é, verificar em sua morfologia os elementos que o alinham como "unidades, conjuntos, séries e relações". Somente assim se pode conceber o "documento" como ação social concreta, e não como exclusiva ação de representação (nesse caso, sempre póstuma) de práticas não discursivas. Ganha corpo crescente na contemporaneidade - e não somente entre os linguistas, mas também entre os historiadores - a compreensão de que é preciso ultrapassar as concepções que encaram o documento textual como mero receptáculo de algo inteiramente pré-constituído fora dele. ${ }^{2}$ Trata-se, em primeiro lugar, de reconsiderar as disparidades, he- 
terogeneidades ou "asperezas" textuais - como eu chamei mais acima as rupturas, contradições e descontinuidades discursivas como aspectos relacionados aos conflitos e disputas nos marcos da ação política, e não somente como contradições derivadas apenas de diferentes modos de interpretar e representar textualmente a realidade contextual.

$\mathrm{Na}$ verdade, é exatamente na superfície do texto que se podem verificar a emergência daqueles novos alinhamentos, daquelas séries de que fala Foucault. Em se tratando da abordagem linguística de textos que "reproduzem o passado" - portanto, em que se presume um grau máximo de "veracidade" - a análise dos corpora textuais que lhe servem como fonte é muito significativa e tem necessariamente que ser explorada, para que não se incorra em equívocos e ingenuidades que, em última instância, comprometem a acuidade analítica perseguida pelo historiador. ${ }^{3}$

Por outro lado, a interpretação de um texto não se situa exclusivamente nos marcos da intenção discursiva de seu autor (cf. ANZ, 2007, 2008), mas constitui-se também fora dele, isto é, fora de seus limites sígnicos. Esta constatação é igualmente relevante do ponto de vista da metodologia do trabalho historiográfico com fontes textuais, embora ela não seja explorada neste texto por razões de espaço. Noto aqui apenas que, exatamente em função das reflexões sobre a relação entre os aspectos textuais e contextuais envolvidas na categorização das produções discursivas propostas por Foucault em sua Arqueologia do Saber, que as reconhece simultaneamente como "práticas discursivas" e "práticas sociais", o conceito de "discurso", bastante variado no campo dos estudiosos da linguagem em sua utilização historiográfica, difere do conceito de "texto". A estrutura de um texto nunca pode ser posta em equivalência com um discurso, sendo antes composta por elocuções (Aussagen) de diferentes discursos. Como eu escrevi acima, no presente texto não entramos no mérito dessa questão. Limito-me a assumir, por motivos de clareza, o termo "discurso" no sentido mais corrente junto ao público não especializado, isto é, como equivalente ao "texto" ou produção linguística concreta, a substância "aparente" no corpus textual. 


\section{Relatos de viagens como objeto de análise específico}

Com base nessas considerações iniciais, examino aqui um pouco mais atentamente um gênero textual específico, os relatos de viagens, com um propósito mais amplo de análise do que eles representam como objeto de reflexão historiográfica e, indiretamente, da prática tradutória.

Ainda que eles possuam em sua constituição genética desde o final da Idade Média um traço fortemente subjetivo, acentuado à medida que se consolidou como gênero discursivo específico originado na era "moderna" 4 , os relatos de viagens também se oferecem como "discursos de veracidade", isto é, como testemunhos que se propõem a repassar experiências, relatar acontecimentos realmente acontecidos no passado. Sejam atuando como entretenimento literário do leitor, sejam como substitutos estéticos correspondentes aos desejos de aventura destes últimos, sejam como alimento para matar a curiosidade diante de novos mundos etnológicos que se descortinavam em função do extraordinário aumento da mobilidade humana, como advertência a futuros viajantes etc. - e possuam eles caráter performativo mais ou menos claros ${ }^{5}-$, os relatos de viagens representam para o investigador contemporâneo um rico manancial como fontes documentais para a atividade historiográfica.

Mas é precisamente este grau híbrido de subjetividade e objetividade, esta condição limítrofe entre ficção e história própria dos relatos de viagens, aquilo que impõe ao tradutor o conhecimento e o manejo de uma moldura teórica e uma metodologia de investigação específica no trabalho com estes corpo$r a$. Destaco apenas dois argumentos a favor desta afirmação. Primeiro, a atividade tradutória, que na maioria dos casos irá permitir o acesso do pesquisador-leitor ao texto como corpus de análise historiográfica, linguística, antropológica etc., não pode prescindir em nenhuma hipótese da reflexão crítica e ativa acerca do ato radical de transposição cultural que o seu fazer representa. Pois os elementos semióticos que materializarão esta transposição são exclusivamente signos linguísticos e visuais, e 
a recriação tradutória de relatos de viagens enquanto "artefatos de cultura" é precisamente o resultado de escolhas sígnicas que emprestarão significado e coerência - fundamentais na atividade de recriação linguística dos contextos históricos pelo historiador - àquelas "asperezas" discursivas (e, por conseguinte, ideológicas) contidas no texto. As reflexões e escolhas do tradutor irão evidenciá-las ou apagá-las, e o resultado incidirá necessariamente no trabalho historiográfico.

O segundo argumento está relacionado com a posição social concreta em que se encontra o tradutor brasileiro, a quem este artigo talvez interesse. Circunstâncias de natureza discursiva, que incidiram sobre a circulação das reflexões historiográficas em nosso país, têm obstado objetivamente a reflexão sobre os relatos de viajantes enquanto objetos específicos, não somente das práticas historiográficas, mas também indiretamente das práticas tradutórias. A reflexão realmente bem informada dos historiadores brasileiros sobre a Nova História (ela própria uma "terceira geração" da École des Annales, que retoma algumas teses fundamentais dos fundadores, entre as quais precisamente as práticas da vida cotidiana, até certo ponto relegadas pela geração braudeliana ${ }^{6}$ ) é bastante retardatária ${ }^{7}$. Isso não pôde deixar de ter reflexos diretos sobre a investigação historiográfica de relatos de viajantes estrangeiros no Brasil, e no mínimo indiretos sobre os interesses editoriais e mercadológicos por traduções de textos dessa natureza. Com base na observação, ainda que superficial, de inúmeros relatos de viagens publicados no Brasil $^{8}$, posso afirmar com convicção que boa parte de seus tradutores - certamente motivados e/ou limitados pelos respectivos interesses editoriais de quem os publicou - pautaram-se com certa frequência por uma visão positivista de linguagem, considerando-a como uma espécie de "recipiente" neutro no qual se depositariam os objetos pré-fabricados dos "fatos" ou "acontecimentos" sócio-históricos. ${ }^{9}$ 


\section{Novas abordagens, novos paradigmas}

Como vemos, é necessária a reflexão sobre o(s) enquadramento(s) teórico(s) e metodologia(s) adequada(s) que dê minimamente conta da natureza e disposição dos elementos constitutivos dos relatos de viagens enquanto campos discursivos próprios, se queremos equacioná-los como objetos específicos da atividade tradutória.

Esta reflexão tem implicado nos últimos anos o acionamento de um conjunto de ações interpretativas mais ou menos conscientes, conforme o maior ou menor conhecimento linguístico do investigador. O acionamento de uma análise do discurso textualmente orientada para o campo da historiografia tem aberto inúmeras possibilidades interpretativas, e se impõem mesmo como obrigatórias quando, por exemplo, se procura tematizar no passado histórico o âmbito da ação individual, das estruturas de personalidade, formas de subjetivização etc. Mesmo algumas publicações oriundas de ambientes historiográficos tradicionais, que revelam em sua compleição editorial uma atitude refratária a estas novas angulações, não deixam de registrá-las. ${ }^{10}$ Uma vincagem importante a ser observada na moderna história da historiografia é o momento em que a linguagem se consolida como elemento fundamental no processo de constituição do campo do conhecimento histórico, ou das "Ciências da História" (Geisteswissenschaften). Naquele momento, na virada do século XVIII para o XIX, cristaliza-se uma autoconsciência historiográfica que redefine e requalifica o trabalho de escolha dos objetos e fontes para o trabalho prático do historiador. Esse processo tem como um de seus momentos determinantes o advento de uma nova semântica do termo "revolução" a partir da grande Revolução Francesa, como observa Koselleck $(2006)^{11}$. Ao trazer consigo uma clara percepção de "aceleração do tempo", a historiografia passa, em finais do século XVIII, a tematizar com crescente intensidade aquilo que hoje chamamos de "tempo presente". Os eventos revolucionários de então estabelecem novas relações entre o historiador e suas fontes históricas. A formação de uma consciência historiográfica vem naturalmente acompanhada da consolidação 
de um crescente sentido de observação, catalogação e preservação dos vestígios materiais e simbólicos considerados como elementos de maior ou menor potencial "discursivo", em termos de explicação do passado histórico. Com esta consciência, os historiadores - tomados aqui como indivíduos que na primeira metade do século XIX passam a desempenhar um novo papel institucional com a autoridade que a nova ciência lhes conferia - começam a determinar quais dentre aquelas fontes e vestígios são mais ou menos relevantes para os fins da interpretação do passado, quais instrumentos e teorias poderiam arrancar estes vestígios de sua condição de objetos "mudos", e através de que modos e associações poderiam investi-los de sentido, a ponto de "fazê-los narrar" naturalmente, isto é, da forma mais coerente e objetiva possível.

É claro que essa nova atitude parte de uma concepção do fazer historiográfico que arranca da capacidade subjetiva do historiador, ao lhe atribuir a "tarefa" - essencialmente linguística - de complementar o "que realmente aconteceu" com o "que [...] chamamos de parte invisível do fato" ${ }^{12}$. Ainda em termos insuficientes, e alicerçada sobre uma concepção de linguagem que nega o seu traço básico de construção essencialmente social, a historiografia dita "romântica" antecipa em mais de um século a condição de centralidade ocupada pela linguagem no ethos do ofício do historiador. Não é um acaso que Wilhelm von Humboldt e Johann Gottfried Herder - que lhe antecedeu na concepção de linguagem como diacronia, desempenho - tenham sido considerados ao mesmo tempo fundadores das assim chamadas "Filosofia da Linguagem" (cf. BAKHTIN, 1999, p. 69-136) e "Filosofia da História" (cf. WEHLING, 2001, p. 21-41), sem as quais não se poderia erigir o edifício das modernas Geschichstwissenschaften.

Em sua Arqueologia, (originalmente publicada em 1969), Foucault registra a tendência da história sua contemporânea em ultrapassar crenças, até certo ponto ingênuas, na possibilidade de "decifração" dos documentos, e localiza precisamente na "crítica do documento" o aspecto-chave do novo fazer histórico. Este novo fazer não mais se propõe a interpretar o documento, tratá-lo como 
"uma voz agora reduzida ao silêncio". O historiador "o organiza, recorta, distribui, ordena e reparte em níveis, estabelece séries”, e procura "definir, no próprio tecido documental, unidades, conjuntos, séries, relações". No mesmo conjunto de corpora onde se divisava a tarefa de "memorizar" o passado, constituem-se hoje "monumentos", "elementos que devem ser isolados, agrupados, tornados pertinentes, interrelacionados, organizados em conjuntos" (FOUCAULT, 2008, p. 7-8). A transformação da disciplina da História em Arqueologia é a consequência de um fazer exegético no qual se estabelece um campo discursivo cujas razões políticas e sociais estão além ou aquém do próprio texto. Ou melhor, em Foucault "a relação das práticas discursivas às práticas não discursivas é ideada em termos de justaposição, sem hierarquia, sem dominância" (ROBIN, 1977, p. 95).

Contudo, como sabemos, não é o discurso, a prática de superfície do desempenho linguístico infinito, que Foucault reclama como objeto de sua análise, e sim as condições de possibilidade desse desempenho ilimitado. Isso deixou em aberto uma lacuna teórica que até hoje ocupa o campo da análise do discurso orientada para a História. Tem-se colocado para o conjunto de estudiosos da História que convivem no campo acadêmico que procuramos apontar no presente ensaio a pergunta acerca da viabilidade de se concretizar teórica e metodologicamente uma perpectiva de trabalho que dê conta dos textos produzidos no passado, tornando-a produtiva para o campo da Historiografia. A essa pergunta observam-se na atualidade duas tentativas de respostas diferenciadas e dignas de menção, no interior do espaço acadêmico de língua alemã. De um lado posiciona-se Philipp Sarasin, que, ao refletir sobre a relação entre História (Geschichtswissenschaft) e Análise do Discurso não considera a hipótese da construção de um método na teoria do discurso que dê conta de forma genérica dos textos do passado. Tratar-se-ia, antes, de uma reflexão filosófica de cada texto singular, com base em autores diversos como Foucault, Lacan, Derrida, Laclau, Mouffe, conforme vão sendo acionadas teorias que deem conta de situações, cuja fixação simbólica (linguística) demanda 
análises caso a caso. ${ }^{13}$ Já Achim Landwehr pleiteia, na esfera da análise do texto, a aplicabilidade de metodologias, por entender que "toda língua possui 'sugestões universais' sociais; ela estrutura a percepção individual e coletiva do que se conhece 'realmente' como experiência (inclusive que causa dissenso quanto à sua qualidade de ser realidade)". Daí se colocar como tarefa da análise do discurso histórico pesquisar "os fatos que são reconhecidos (...) como dados em sua mediação linguística e social em um dado tempo" (KELLER, 2005, p. 13)14.

\section{Delimitação do objeto de investigação}

Não cabe aqui o exame, ainda que com um mínimo de amplitude analítica, dos aspectos contidos nas duas alternativas, pois isso equivaleria a implodir as dimensões deste texto. $\mathrm{O}$ excurso serve apenas para apontar a tensão teórica existente mesmo entre os pesquisadores que se alinham à perspectiva sistematizada por Foucault. Proponho-me, neste momento, e com vistas a avançar algumas reflexões úteis voltadas para quem trabalha com o "gênero" relatos de viagens como objeto da prática tradutória, a me interrogar sobre quais teorias e métodos disponíveis podem se mostrar produtivos em termos de resultados finais que beneficiem os estudos históricos nesse campo.

Quais os elementos envolvidos na ação discursiva que tem por corpus um relato de viagem? Podemos classificá-los segundo sua morfologia, suas determinações mais relevantes como práticas discursivas e como práticas sociais específicas. Longe de tentar estabelecer uma tipologia mais precisa, limito-me a esboçar em linhas gerais algumas balizas para essa classificação com vistas à reflexão que auxilie o fazer tradutório desse corpus específico.

No que respeita às suas formas possíveis, o relato pode constituir um todo ou somente um fragmento: livro, diário, carta, relatório, auto-informe-confissão ${ }^{15}$, anotações esparsas etc. Evidentemente, diversos elementos de cada uma destas formas (como 
temas, modos de enunciação, conceitos empregados etc.) podem estar - e supõe-se que normalmente estão - presentes em cada uma delas, constituindo assim formas textuais híbridas.

Entre as determinações do relato de viagem enquanto práticas discursivas destacam-se a sua gênese, circulação e destinação.

Em sua gênese, papel talvez preponderante desempenhe a projeção ou estabelecimento hipotético do(s) receptor(es). Nesse sentido, o texto pode dirigir-se somente a um ou a vários indivíduos. Num ou noutro caso, importa saber o perfil imaginado do(s) leitor(es) em termos etários, sociais, econômicos, geográficos, culturais etc. Projeta-se um leitor médio de um público relativamente homogêneo, ou projetam-se leitores múltiplos no interior de um público heterogêneo. Nesse último caso, importa definir quais são as características ou elementos que balizam esta heterogeneidade/ homogeneidade.

Entre as instituições que definem a circulação de um relato de viagem (supondo que ele circule como publicação autônoma, e não fique encerrado em alguma gaveta ou arquivo como carta, auto-informe-confissão, fragmento etc.), podemos supor as ações próprias do mercado editorial, claramente observáveis na primeira metade do século XIX com a emergência de públicos massivos ávidos pelo gênero, a incidência da ação de instituições privadas de diversas naturezas, estatais, de apoios ou impedimentos institucionais, de censura, de manipulação e/ou ocultação de informações etc. Uma viagem e seu relato podem colocar-se a serviço de um projeto (neo) colonial, de fixação de (auto)identidades nacionais, familiares, de clã ou de estamentos. Pode prover governos de informações voltadas a migrações, transações comerciais, turísticas etc.

Quanto à sua destinação, um relato pode ser redigido a partir de anotações feitas como (ou a partir de) anotações (inteira ou parcialmente) alheias à finalidade de publicação, como diários, autobiografias, anotações autoconfessionais, cartas, apontamentos etc. Como artefato destinado ao público, ele pode ser resultado de uma incumbência, de uma demanda do mercado editorial, ou de apontamentos realizados com essa finalidade para servirem de base 
para outros textos. Por outro lado, uma viagem pode se constituir num ensejo inesperado para a escrita de um relato, ou pode ter sido planejada e executada precipuamente para este fim.

Portanto, as motivações textuais, discursivas e sociais que condicionam a formação do campo discursivo no qual se inserem os relatos de viagens são complexas, podendo apresentar inúmeros aspectos e matizes de intensidade. Em consequência, seria ingênuo considerá-los exclusivamente como meio exclusivo de transmissão de uma determinada realidade ou experiência vivida a partir de um deslocamento no espaço e no tempo. Antes devemos considerá-los como um conjunto de práticas que, de forma dialética, simultaneamente representam, agem socialmente e estabelecem objetos e sujeitos, isto é, identidades.

\section{A Análise do Discurso Crítica (ADC)}

Em meio a tantos elementos, como pensar em teoria(s) ou método(s) que trate(m) de uma prática simultaneamente discursiva, social e identitária? Por outro lado, como garantir que todas essas reflexões não se limitem à investigação do campo das práticas discursivas exclusivas do momento presente? Como garantir que estas reflexões assumam profundidade histórica, que possam tornar-se um exercício historiográfico e epistemológico que possa romper com um presentismo ao qual um sem-número de teorias do discurso condena toda e qualquer análise do discurso, como uma espécie de camisa-de-força obrigatória e inescapável?

Em meio ao cipoal de acontecimentos e produções acadêmicas dos últimos 20 anos torna-se certamente imperativa uma delimitação mais precisa do alcance desta dimensão linguística na reflexão historiográfica, sob pena de deixarmo-nos confundir com correntes de pensamento que pura e simplesmente reduzam toda a problemática do exame de textos e documentos escritos no passado ao âmbito exclusivo do texto. Retorna-se, assim, à pretensão da instituição da Linguística como espécie de Arquiciência, que relega 
silenciosamente o campo das investigações da História ao limbo de um ethos subalterno no campo das Ciências Humanas.

As dimensões deste texto não permitem uma conceituação mais ampla do campo de investigação geralmente denominado como "Análise de Discurso Crítica" (doravante ADC). Limito-me, a título de demarcação do campo até certo ponto imprecisa, a mencionar como emblemático o "Manifesto" do britânico Norman Fairclough ao final de seu manual Analysing discourse como tentativa de síntese (não inteiramente desprovida de aspectos problemáticos) (FAIRCLOUGH, 2003, p. 202-211).

Destaco três aspectos centrais da ADC proposta pelo autor. Em primeiro lugar, ela reconhece que as esferas das relações sociais, das identidades sociais, dos valores e consciência culturais, entre outros, são somente em parte discursivos, pois contém elementos não redutíveis à esfera exclusiva do discurso; assim, o modo como são teorizadas e pesquisadas as relacões sociais não podem ser os mesmos com os quais é teorizada e pesquisada a linguagem (FAIRCLOUGH, 2003, p. 205). Em segundo lugar, o autor delineia - como desdobramento da análise tridimensional proposta em sua obra Discurso e mudança social (1991) - a possibilidade de investigação de um determinado discurso enquanto prática social na medida em que (1) desempenha atividade social no interior de uma prática da qual faz parte (como, por exemplo, no trabalho), (2) representa outras práticas - o que inclui a autorrepresentação reflexiva - e (3) constitui identidades. Por último, a ADC invoca como elementos de análise as "ordens sociais" construídas pelo discurso. A exemplo de seu emprego em corpora da contemporaneidade supõe-se que a teoria de Fairclough também possa dar conta do ordenamento social das relações entre diferentes modos de significação realizados no passado, como é o caso textual dos relatos de viagens. Do mesmo modo que outros artefatos textuais da vida contemporânea, os relatos criavam, no momento mesmo de sua constituição, discursos dominantes e discursos marginais, trazendo consigo um corolário de questões políticas e ideológicas envolvidas nesta ação segregadora (nomea- 
damente questões relacionadas à busca de hegemonia e às reações de resistência).

Embora as reflexões e análises de Norman Fairclough estejam centralmente voltadas para a contemporaneidade, definindo como sua arena de pesquisa o que o autor denomina de new-capitalism contemporâneo, reconheço como muito promissor o potencial de sua abordagem investigativa quando empregada no estudo da história dos artefatos textuais do passado. Mas não como o único. Autores como Franz Eder, Reiner Keller, Peter Haslinger, Rüdiger Graf, Andreas Frings, Johannes Marx e Claudia Bruns, para mencionar apenas os autores que formam o importante número temático da Österreichische Zeitschrift für Geschichtswissenschaften $(2005)^{16}$, compõem um grupo que contribui com significativas reflexões nesse campo, articulando não somente autores de língua alemã, mas igualmente franceses e norte-americanos. Particularmente proveitosas me parecem às sugestões de Haslinger sistematizadas ao final de seu ensaio na revista, em que sugere um modelo para uma História do Discurso ampliada. Nesse modelo, Haslinger propõe os passos de trabalho em cinco níveis, cujas subdivisões estruturam-se em sua maior parte na seguinte sequência: (1) Corpus e profundidade de focalização; (2) Medialidade e contexto; (3) Análise textual; (4) Análise do discurso; e (5) Classificação de cada um dos resultados num quadro geral do discurso investigado.

As propostas de Fairclough e de Haslinger são apenas dois exemplos entre diversos outros não mencionados aqui, mas que conformam o campo bem mais amplo da Análise do Discurso Crítica.

\section{Tradução de relatos de viagens como dimensão da práxis historiográfica}

A escolha de um determinado relato de viagem em língua estrangeira como objeto de tradução para a língua vernácula configura em si mesma uma prática discursiva específica que repercute no campo da investigação histórica, onde quer que seja realizada. 
Centenas são os viajantes, nas mais diferentes línguas; inúmeros são os recortes possíveis, desde o início da chamada "Modernidade Antiga" ${ }^{17}$ aos dias de hoje. Milhares de páginas se oferecem em diferentes corpora e em diferentes extensões.

Contudo, o trabalho de levantamento e disponibilização dos relatos de viajantes produzidos num determinado período histórico para qualquer língua vernácula não esgota o trabalho arquivístico de levantamento das fontes fundamentais relacionadas a essa pesquisa histórica. Em cada época específica, o texto-documento proporá um diálogo com o pesquisador. $\mathrm{O}(\mathrm{A})$ viajante-autor(a), não considerado(a) como mônada, mas como radicalmente atravessado(a) por discursos, concretiza(m) em seu relato a materialização sígnica desses discursos. A prospecção desses discursos tornados textos, a sua interpretação produtiva para a história compõe, assim, de forma sempre nova, nunca acabada, completa, um campo complexo de relações em que a análise do artefato textual não responde inteiramente pelo evento representacional, acional e ideacional agenciado por este artefato.

Por outro lado, o historiador procura nesse objeto respostas ou pistas com as quais sua época tenta ler o presente. Há muito ele não recorre mais à história do passado como magistra vitae, mas como uma espécie de outro, de diferente, com o qual constroi o seu fazer discursivo. Este, não mais o mero registro post factum dos acontecimentos, insere-se em sua contemporaneidade na condição de praxis, no sentido mais autêntico de ação histórica voltada para o futuro.

Nestas circunstâncias, o relato de viagem como corpus para práticas tradutórias vê-se destituído de sua condição estável, tranquila, que supõe soluções generalizantes e métodos sempre previsíveis para os problemas de translação linguística que se apresentam. Como pretendi mostrar ao longo deste breve ensaio, esta modalidade textual reclama não somente a reflexão sobre a prática tradutória textual, propriamente dita, mas igualmente sobre seu ethos, simultaneamente arquivístico e historiográfico, cujas escolhas e decisões ultrapassam a problemática encerrada na superfície do texto a ser transladado. De forma paralela às tendências de pesquisa que suge- 
rem contemporaneamente a ultrapassagem da Análise do Discurso histórico, e a sua substituição pela História do Discurso (cf. HASLINGER, 2005, p. 33 e passim), sugiro, para efeito de conclusão, a ultrapassagem das vertentes tradutórias que supõem fórmulas essencialmente técnicas para o conjunto de problemas encerrados na prática de translação, invocando para tanto o exemplo da reflexão historiográfica. Não é mais plausível se pensar na resolução de problemas semânticos postos por textos do passado apenas através do seu esbatimento num plano "chapado" do presentismo, isto é, somente preocupado com a circunstância hermenêutica da leitura do resultado da prática tradutória, desconsiderando toda a dimensão extralinguística envolvida nesta atividade. Ainda que em última análise inscritas na superfície do texto-resultado da tradução, estes procedimentos, a exemplo do que acontece com a análise do discurso historicamente orientada, não podem ficar restritos à matéria exclusivamente linguística, devendo, antes, acionar elementos reflexivos possivelmente mais afeitos à Historiografia e à Escrita da História. Cabe aos que exercem o ofício da tradução refletir, com base no que foi dito neste texto, sobre a problemática, os objetos, os métodos e passos de trabalho específicos postos como exigência de modo geral pelos documentos textuais do passado, e, em particular, pelos relatos de viagens como objetos específicos.

\section{Notas}

1. O autor define a "língua" como "sistema para enunciados possíveis - um conjunto finito de regras que autoriza um número infinito de desempenhos", distinguindo-a do "campo dos acontecimentos discursivos", "conjunto sempre finito e efetivamente limitado das únicas sequências linguísticas que tenham sido formuladas", para apontar seu interesse central na investigação deste último, e não o plano do "número infinito de desempenhos" possíveis (FOUCAULT, 2008, p. 30). 
2. Em ambiente de língua alemã, as perspectivas de pesquisas dos anos mais recentes na área das Ciências Sociais (Sozialwissenschaften) que estudam mais detidamente teorias do discurso têm em comum, segundo Reiner Keller, além da rejeição do uso normativo do conceito de discurso de Habermas e daquele tipo de "discourse analysis" que nada mais faz do que a análise etno-metodológica ou linguístico-pragmática de conversações com vistas à "organização do uso concreto da língua em sequências linguísticas curtas”, a encampação da programática da pesquisa do discurso apoiada teoricamente em Michel Foucault e outros pós-estruturalistas, além de Ernesto Laclau, Chantal Mouffe e outros de tradição marxista (KELLER, 2005, p. 11).

3. Todo historiador é até certo ponto consciente da ingenuidade do ato utópico de se apropriar do passado através de textos. Melhor que ninguém ele sabe quando quem escreve amalgama em seus textos explicações causais, pratica a supressão das disjunções do mundo real através de sua atividade subjetiva, etc. "Contudo", afirma o próprio Philipp Sarasin, reconhecido como um teórico da história que, ao contrário de outros de língua alemã, revela-se cético com relação às aspirações de se abordar as questões de análise do discurso com bases em métodos generalizantes, e postula antes uma análise crítico-filosófica em cada caso específico, "deve ser concedido ao historiador que o seu procedimento não somente é praticável, como também inteiramente incontornável no sentido pragmático: textos têm de ser 'compreendidos' em qualquer circunstância, ao menos em seu sentido manifesto. Ainda que esta compreensão seja imaginária - ela é sem dúvida o primeiro modo no qual historiadores têm que trabalhar os seus textos-fonte" (SARASIN, 2006, p. 60).

4. O termo "modernidade" é aqui utilizado na acepção koselleckiana como um interregno que projeta uma perspectiva radicalmente nova de presente, muito mais prospectiva em direção a um futuro aberto e desconhecido (cf. KOSELLECK, 2006), e que, por isso mesmo, paradoxalmente empresta à escrita historiográfica um caráter mais subjetivo, pois condiciona a necessidade de reelaboração, de reescrita do passado à virtude narrativa do historiador. Walter Schmitz registra o mesmo paradoxo por outro ângulo: a viagem logo após 1800 põe em dúvida a intenção de se adquirir conhecimentos úteis e uma verdadeira ciência. Viagem não funda mais mal-estar e insegurança, mas liberação; relatos de viagem tornam-se o encontro consigo mesmo. A finalidade é o caminho, não o destino final. Não se busca mais a Bildung, mas a aventura (SCHMITZ, 2005, p. 15).

5. Dada a sua condição discursiva ao mesmo tempo objetiva e subjetiva, pois textos narrativos reproduzem um acontecimento, enquanto os líricos se esforçam por serem acontecimentos (cf. CULLER, 2002, p. 113). 
6. “A verdadeira ruptura ocorrida na historiografia francesa e responsável pela irrupção da chamada Nova História, particularmente da história das mentalidades, parece ter ocorrido muito mais em relação à 'era Braudel', na qual predominou uma visão totalizante e socioeconômica da história, do que em relação aos primórdios dos Annales, tempo em que as mentalidades eram valorizadas" (VAINFAS, 1997, p. 135).

7. "A Nova História tardou muito a penetrar no âmbito da historiografia brasileira, só o fazendo, a rigor, a partir de meados da década de 1980, tempo em que as 'mentalidades' já estavam em processo de reformulação na França e a Nova História cultural despontava como sua principal 'herdeira'" (VAINFAS, 1997, p. 158). Existiu mesmo uma confusão entre História das Mentalidades, História Cultural e Micro-história, e muitas acusações e resistências ao que se tomava por Nova História erravam frequentemente de alvo. "O atraso de 10 ou 15 anos que marcou a difusão dessas correntes no Brasil foi, em grande parte, responsável por tais confusões, pois todas essas inovações da historiografia, principalmente europeia, chegaram juntas ou, pelo menos, se difundiram juntas nos anos 1980" (VAINFAS, 2009, p. 233).

8. Referência fundamental aqui tem sido BERGER, 1980.

9. Ainda que bastante afastado no tempo, menciono aqui um exemplo bastante representativo desta concepção. Em minhas pesquisas na Biblioteca Nacional no Rio de Janeiro, quando iniciei a procura pelo relato da passagem da austríaca Ida Pfeiffer no Rio de Janeiro, deparei-me com o livro de Affonso Taunay intitulado No Brasil de 1840 (1935). Nele, a passagem de Pfeiffer no Brasil é recontada na terceira pessoa pelo autor. Com isso, toda a possível pesquisa sobre a dimensão estética e as condições de surgimento do relato de Pfeiffer, Viagem de ита тиlher ao redor do mundo (Eine Frauenfahrt um die Welt, de 1850), a circulação e recepção da obra junto aos contemporâneos, bem como seu papel na criação de estereótipos eurocêntricos, que mais tarde retornarão como muitos outros, num movimento circular, ao Brasil (alguns permanecendo até os dias de hoje) etc., são sumariamente desconsiderados.

10. Embora não façam muito mais do que mencionarem as novas abordagens e paradigmas, crises de paradigmas e turns diversos, invocando os cruzamentos interdisciplinares com a psicologia, a etnologia e a antropologia histórica, mas reservando à linguística uma condição bastante lateral (cf. o artigo de TANNER \& HUNT na coletânea de Hans-Jürgen Goertz, Geschichte. Ein Grundkurs). 
11. A partir de 1789 "cristaliza-se em um coletivo singular, que parece concentrar em si a trajetória de todas as revoluções particulares. É assim que a revolução torna-se um conceito meta-histórico, separando-se completamente de sua origem natural e passando a ter por objetivo ordenar historicamente as experiências de convulsão social” (KOSELLEK, 2006, p. 69).

12. Em 1821, Wilhelm von Humboldt atesta: "Visto por este lado, o historiador é autônomo, e até mesmo criativo; e não na medida em que produz o que não está previamente dado, mas na medida em que, com sua própria força, dá forma ao que realmente é, algo impossível de ser obtido sendo meramente receptivo. De um modo diverso ao do poeta, mas ainda assim guardando com este semelhanças, o historiador precisa compor um todo a partir de um conjunto de fragmentos" (HUMBOLDT, 2001, p. 60).

13. "O maior desafio da teoria do discurso à escrita da história não consiste em pensar na discursividade, e, com isso, em certo sentido na 'ficionalidade' de realidades passadas, como sempre se adverte como sendo periogoso. Mais emocionante e difícil é a questão: onde, em todas as estruturas simbolicamente reconstituíveis, que tornam perceptível a realidade social, se mostram os limites dessas estruturas, e com eles o real que as constitui?" (SARASIN, 2006, p. 76).

14. "O primeiro passo para a concretização metodológica consiste, segundo Landwehr, na afirmação da 'positividade' das elocuções [Aussagen]. Essa suposição, corrente na teoria do discurso, formulada em conexão com Michel Foucault, volta-se contra os procedimentos hermenêutico-compreensivos que procuram nos documentos em questão por algum 'suposto sentido' ou uma grandeza de referência 'por detrás do texto' (por exemplo, uma situação de classe)". De fato, Landwehr não renuncia à atividade hermenêutica, apenas se recusa a aceitar "a visão como que ingênua de textos como unidades dotadas de coerência de sentido e como expressão controlada de seus autores" (KELLER, 2005, p. 13-14).

15. Revelação ou testemunho de "ato [que] carece de uma determinidade de fins, de meios, e não de uma determinidade do seu agente - a personagem. O próprio ato nada diz do atuante, diz apenas de sua ambiência material, e não é a personagem mas tão-somente essa ambiência que gera o ato" (BAKHTIN, 2003, p. 129).

16. Que tem por título "Das Gerede vom Diskurs - Diskursanalyse und Geschichte" (A fala do discurso - Análise do Discurso e História). 
17. "Neuzeit" ou "Modernidade" foi um conceito de periodização que remonta a Ch. Cellarius (1638-1707), filólogo e historiador de Halle, que se referia ao fim do período medieval. Com o advento das grandes navegações se afirmou, por longo período, como o interregno a partir da descoberta da América em 1492 e o início da Reforma de Lutero em 1517. A "Modernidade Antiga" ou "Frühe Neuzeit" é ainda hoje funcionalizada pela historiografia como referência ao período inicial desta "Modernidade" (Cf. MEYERS LEXIKON,1991, p. 292).

\section{Referências}

ANZ, Heinrich. Hermeneutik und Ethik des Textverstehens. Palestra no Ciclo Theorien und Methoden der Literatur- und Kulturwissenschaft, Universidade de Freiburg, 2007/2008. Disponível em: < http://podcasts.uni-freiburg.de/podcast_ content?id_content $=29>$. Acesso em: 13/12/2013

BAKHTIN, Mikhail. Os gêneros do discurso. In: verbal. 4. ed. São Paulo: Martins Fontes, 2003. p. $\overline{261-306 .}$

Estética da criação

. Marxismo e filosofia da linguagem. 9. ed. São Paulo: Hucitec, 1999.

BERGER, Paulo. Bibliografia do Rio de Janeiro 1531-1900. 2. ed. aumentada e revista. Rio de Janeiro: SEEC-RJ, 1980.

CULLER, Jonathan. Literaturtheorie: Eine kurze Einführung. Stuttgart: Phillip Reclam, 2002.

FAIRCLOUGH, Norman. Manifesto. In: Analisyng discourse: Textual analysis for social research. London and New York: Routledge, 2003. p. 202-11.

FOUCAULT, Michel. A arqueologia do saber. 7. ed. Rio de Janeiro: Forense Universitária, 2008. 
HASLINGER, Peter. Diskurs, Sprache, Zeit, Identität. Plädoyer für eine erweiterte Diskursgeschichte. In: EDER, Franz X. (Hg.). Das Gerede vom Diskurs: Diskursanalyse und Geschichte. Österreichische Zeitschrift für Geschichtswissenschaften, 16. Jg., Heft 4. Innsbruck: Studienverlag, 2005. p. 33-60.

HUMBOLDT, Wilhelm von. Sobre a tarefa do historiador. Anima: História, teoria e cultura. Rio de Janeiro, Casa da Imagem/PUC-Rio, ano 1, n. 2, p. 79-89, 2001.

KELLER, Reiner. Wissen oder Sprache?: Für eine wissensanalytische Profilierung der Diskursforschung. In: EDER, Franz X. (Hg.). Das Gerede vom Diskurs: Diskursanalyse und Geschichte. Österreichische Zeitschrift für Geschichtswissenschaften, 16. Jg., Heft 4. Innsbruck: Studienverlag, 2005. p. 11-32.

KOSELLECK, Reinhart. Modernidade: Sobre a semântica dos conceitos de movimento na modernidade. In: Futuro passado: Contribuição à semântica dos tempos históricos. Rio de Janeiro: Contraponto, 2006. p. 267-303.

MEYERS. Meyers Kleine Lexikon Geschichte. 2. ed.. Mannheim: Lexikonsverlag, 1991.

ROBIN, Régine. História e Linguística. São Paulo: Cultrix, 1977.

SARASIN, Philipp. Diskurstheorie und Geschichtswissenschaft. In: KELLER, Reiner et alii (Hrsg.). Handbuch Sozialwissenschaftliche Diskursanalyse. Band 1 - Theorien und Methoden, Band 1. 2. ed. Wiesbaden: VS Verlag für Sozialwissenschaften, 2006. p.55-81.

SCHMITZ, Walter. Mobilität des Menschen: Zur geschichtlichen Konstruktion von Räumen der Bewegung. In: REHBERG, Karl-Siegbert, SCHMITZ, Walter, STROHSCHNEIDER, Peter (Hsg.). Mobilität, Raum, Kultur: Erfahrungswandel vom Mittelalter bis zur Gegenwart, v. 1. Dresden: Verlag Thelem, 2005. p. $1-22$.

TANNER, Jakob, HUNT, Lynn. Psychologie, Etnologie, Historische Anthropologie. In: GOERTZ, Hans-Jürgen (Hg.). Geschichte: Ein Grundkurs. 3. ed. Hamburg: Rowohlt, 2007. p. 737-65. 
VAINFAS, Ronaldo. História cultural e historiografia brasileira. História: Questões \& Debates, Curitiba, n. 50, p. 217-235, Editora UFPR, jan./jun. 2009.

. História das mentalidade e história cultural. In: CARDOSO, Ciro Flamarion, __ Domínios da história: Ensaios de Teoria e Metodologia. 5. ed. Rio de Janeiro: Campus, 1997. p. 127-62.

WEHLING, Arno. A invenção da história: Estudos sobre o historicismo. 2. ed. Rio de Janeiro: Gama Filho, 2001.

Recebido em: 12/02/2014 Aceito em: 23/05/2014 